\title{
GIS IN URBAN GEOLOGY: THE CASE STUDY OF NAFPLIO, ARGOLIS PREFECTURE, GREECE
}

\author{
Zervakou A.D. ${ }^{1}$ and Tsombos P.I. ${ }^{1}$ \\ ${ }^{1}$ Institute of Geology and Mineral Exploration (I.G.M.E.), Olympic Village, 3rd Entrance, 13677 Acharnae, \\ Greece,zervakou@igme.gr,ptsombos@igme.gr
}

\begin{abstract}
The aggregation of population in big cities leads to the concentration of human activities, overconsumption of natural resources and urban growth without spatial planning and sustainable management. As a result, urban societies are exposed to various dangers and threats with economic, social, ecological, and environmental impacts on the urban surroundings. Problems associated with urban development are related to the existing geological conditions. Therefore, the provision of appropriate geological information about the urban environment is essential for every sustainable urban planning. The first systematic recording, codification and documentation of "Urban Geology" geothematic information in Greece was implemented by the Institute of Geology and Mineral Exploration (I.G.M.E.) in the framework of the project called "Collection, codification and documentation of geothematic information for urban and suburban areas in Greece - pilot applications". Through the implementation of this project, geological mapping, geotechnical, geochemical, geophysical research and measurements took place at four pilot cities of Greece. Nafplio, the capital city of Argolis prefecture, was one of them. During the project, all compiled data were stored and processed in specially designed geodatabases in GIS environment in order to produce multifunctional geothematic maps and other digital products (DEMs, 2D - 3D surfaces).
\end{abstract}

Key words: Urban Geology, geothematic information, GIS, Nafplio.

\section{Introduction}

According to current estimates, cities occupy $4 \%$ or less of the world's terrestrial surface, yet they are home to almost half of the global population, consume close to three-quarters of the world's natural resources and generate three-quarters of its pollution and wastes.

Urban areas expanding dramatically quickly, often without sustainable planning, are more at risk than other areas. Their dependence on natural factors such as geology, topography, proximity to hazard sources and intensive human activities arise the disaster risk. Hence, the urbanization process in developing countries is indicative of a process that needs considerable attention.

Given that the Earth's population will in future be concentrated into 'mega-cities', with the attendant problems associated with the concentration of the human race into a small part of the Earth's land surface, an increasing focus for geologists is the urban environment.

The basic role of the Institute of Geology and Mineral Exploration of Greece (I.G.M.E.) regarding urban geological information is to increase the utilization and facilitate the dissemination of geo- 
logical data for urban planning and risk management. I.G.M.E. can provide the planners and other interested parties with geological data easily understood by non-geologist users.

In this paper we demonstrate how the multifunctional technology of Geographic Information Systems (GIS) was used in order to collect, store, manage, process, analyze and cartographically represent the complex geoscientific information derived from Urban Geology studies, carried out by IGME, with an emphasis given in Nafplio.

\section{Urban Geology}

Essential to effective urban planning is the availability of accurate, understandable, and pertinent data on Urban Geology that decision-makers can use in making informed choices. Unfortunately, geological information is an underused resource in planning, despite the fact that the majority of cities owe their historical development to geological factors.

Urban Geology is a relatively new branch of the earth sciences that came into life in the past fifty years. It is the study or application of geology to urban centers, urban development and planning. The importance of geology as applied to cities has been stressed repeatedly by Legget (1973) and Legget and Karrow (1983).

Urban Geology is not only important for every urban centre or city, it is also site specific. Each city with its unique set of geological settings and geological constraints poses different or unique sets of problems for the engineers and developers. Since all construction and development works are sited on/in earth materials, it is geology that will indicate the types of problems that are encountered at each site/city (Tan et al., 1990).

Urban geologists have actually three broad tasks (Hancock and Skinner, 2000):

- to manage the provision of mineral, construction, water, and conservation resources,

- to provide appropriate geological information for construction, engineering, and waste-management projects and

- to manage and mitigate the natural and human-induced hazards that threaten an increasingly concentrated and therefore vulnerable urban population.

An Urban Geology project provides the opportunity to compile all the geoscience information available for capital cities and release the information in a standard format that could be accessible to all users including the private sector, the various levels of governments, universities and the general public (Bélanger and Moore, 1999).

The last decades, globally, many geological surveys and other institutes have operated "Urban Geology" programs aiming to provide up-to-date information on ground-related issues for the towns and cities. Through the collection and compilation of geological data, Urban Geology projects contribute:

- to the identification and evaluation of geohazards,

- to the development of countermeasures to reduce them,

- to the preservation of urban and surrounding environment.

\section{The case study of Nafplio, Argolis prefecture}

The first systematic recording, codification and documentation of Urban Geology geothematic information in Greece was implemented by the Institute of Geology and Mineral Exploration (I.G.M.E.) in the framework of the project called "Collection, codification and documentation of geothematic information for urban and suburban areas in Greece - pilot applications". 

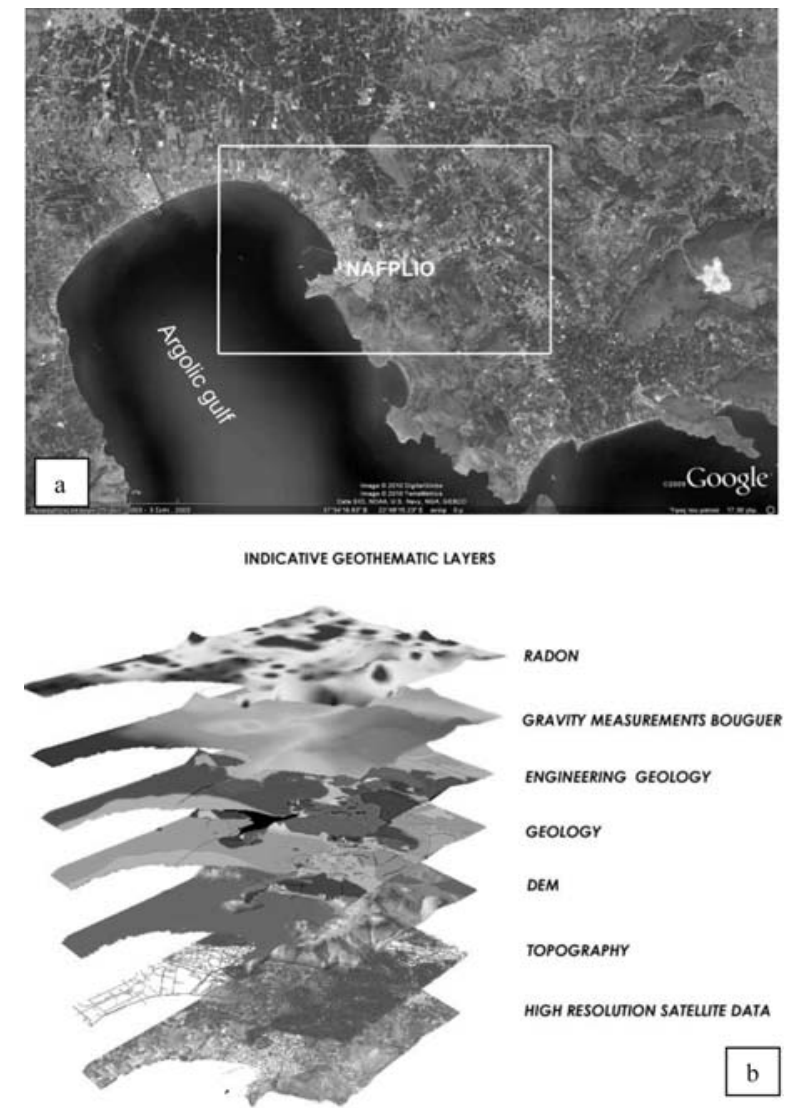

Fig. 1: (a) Satellite image from Google Earth showing the study area (included within the white box), (b) Indicative diagram of Urban Geology geothematic layers produced through "Urban Geology" project of I.G.M.E. (Pantelias et al., 2008).

The third subproject called "Integrated geological, geotechnical, hydrogeological, geochemical, geophysical and marine studies in urban and suburban area of Nafplio, Argolis Prefecture" took place at the broader area of Nafplio (Fig. 1a).

The aim of the project was the compilation of existing geoinformation concerning geological, hydrogeological, geotechnical, geochemical and geophysical reports for urban and suburban areas over the whole country in databases. At the same time, desk and field survey was carried out. All information derived from geological mapping, geotechnical - geochemical - geophysical - marine research and measurements was stored and processed in spatial databases, specially designed for the demands of the specific project, in GIS environment. The project's results are presented in geothematic maps and other digital products.

\subsection{Project outline}

An Urban Geology project should compile and release all the available information for the specific area. This includes all properties of the bedrock and surficial materials, aquifers, geochemistry, geotechnical characteristics and other parameters. There is a need for site-specific information such as 
geological maps at a large scale (1:5.000, 1:1.000), stratigraphic cross-sections, topographic maps (1:5.000 scale), logs from boreholes, soil and water sampling, etc. Users, including public and private sector, demand information as detailed and specific as possible and at a scale as large as possible.

As mentioned above, the specific Urban Geology project focused on the collection and integration of field work - laboratorial - processed data derived from various sources, summarized to the following (Zervakou et al., 2007):

- Geological mapping at 1:5.000 scale for the identification and evaluation of geological settings in the study area.

- Neotectonic mapping at 1:5.000 scale for the identification and evaluation of active faults in the study area.

- Geotechnical mapping at 1:5.000 scale for the identification and evaluation of physical, mechanical and geotechnical properties of geological formations in the study area.

- Geotechnical survey and sampling in 22 locations.

- Geotechnical rock mass classification in 22 locations (according to Bieniawski).

- Hydrogeological survey.

- Geochemical survey.

- Water and soil field sampling for geochemical analyses.

- Radon measurements.

- Surface Geophysical survey.

- Deep Geophysical survey.

- Marine geological survey.

- Geoarchaelogical survey.

\subsection{Geographic Information System}

To store, describe and process the complex information derived from field work and laboratory processing, GIS technology was chosen as the best solution for the input, storage, management, analysis and cartographic representation of such geographic information. The software used for the development of the specific GIS application was ArcGIS 9x, ArcInfo version, ESRI.

GIS elaboration comprised the following stages (Zervakou et al., 2007):

- Design and building of the geographic database.

- Data import (Digitizing, GPS points, etc.).

- Descriptive information and hyperlink input.

- Data management (transformations, topology, editing, etc).

- DEMs and other surfaces generation.

- Thematic maps compilation.

\subsection{Geodatabase schema and contents}

The real world is too complex for our immediate and direct understanding. For this reason we create "models" of reality that are intended to have some similarity with selected aspects of the real world. Databases are created from these "models" as a fundamental step in coming to know the nature and status of that reality. A spatial database is a collection of spatially referenced data that acts as a model of reality in the sense that the database represents a selected set or approximation of phenomena (Goodchild and Kemp, 1990). 


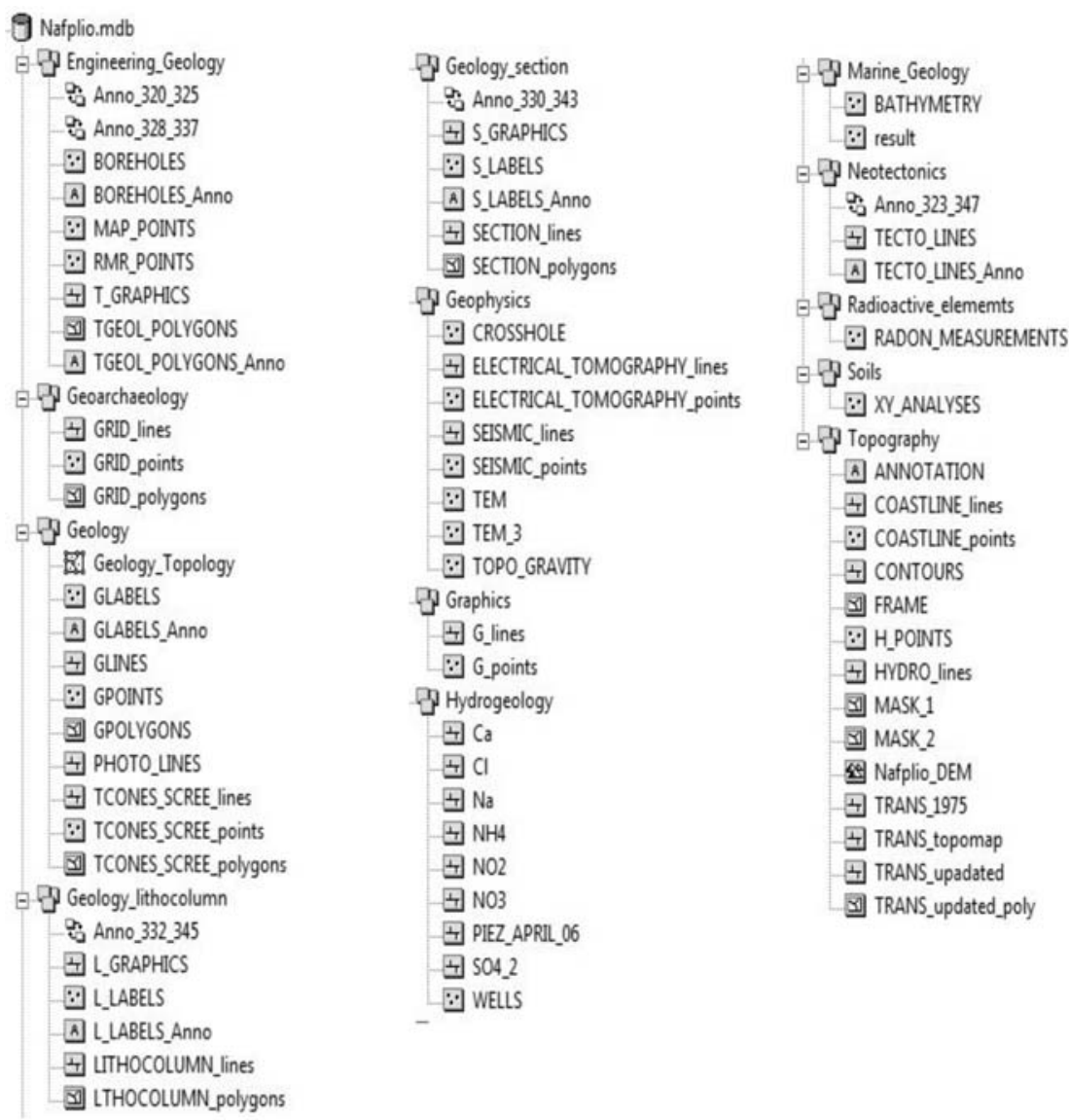

Fig. 2: "Nafplio" Geodatabase schema and contents.

A spatial database is designed to store, query, and manipulate geographic information and spatial data. It is also known as a geodatabase.Within a spatial database, spatial data is treated as any other data type. Vector data can be stored as point, line or polygon data types, and may have an associated spatial reference system. Some geodatabases also include support for storing raster data.

For the specific GIS application an ArcGIS Personal Geodatabase was built. Personal geodatabases are much like file-based workspaces. Microsoft Access is used to work with attribute tables in such geodatabases. They support single user editing and no versioning support is provided. All geographic data are stored in feature classes, classified in different Feature Datasets and single tables containing additional information. The used projected coordinate system is the Greek Geodetic Reference System EGSA'87 (Datum: D_GGRS_1987, Spheroid: GRS_1980).

In particular, the "Nafplio" Geodatabase (Fig. 2) contains the following feature datasets which comprise thematically related feature classes (Zervakou et al., 2008):

- Feature dataset Topography: Topographic data derived from four topographic maps of the Geographic Military Service at 1:5000 scale, covering the study area. 


\begin{tabular}{|c|c|c|c|c|}
\hline \multicolumn{5}{|c|}{ Topology Rules } \\
\hline \multirow[t]{11}{*}{ Name } & Origin (FeatureClass:-Subtype) & Rule Type & Destination (FeatureClass::Subtype) & Trigger Events \\
\hline & Glines:: Opio & Must be covered by boundary of & Gpolygons: : All Subtypes & No \\
\hline & Glines:: Opio & Must not have dangles & Glines:: Opı & No \\
\hline & Gpolygons: : All Subtypes & Must not have overlaps & Gpolygons: : All Subtypes & No \\
\hline & Gpolygons:: All Subtypes & Boundary must be covered by & Glines:: Opıa & No \\
\hline & Gpolygons: : All Subtypes & Must not have gaps & Gpolygons: : All Subtypes & No \\
\hline & GLabels:: All Subtypes & Must be properly inside polygons & Gpolygons: : All Subtypes & No \\
\hline & Glines: All Subtypes & Must not overlap & Glines: All Subtypes & No \\
\hline & Glines:: Opia & Must not intersect & Gines:: Opia & No \\
\hline & Glines:: All Subtypes & Must not self overlap & Gines:: All Subtypes & No \\
\hline & Glines:: All Subtypes & Must not self intersect & Glines:: All Subtypes & No \\
\hline
\end{tabular}

Fig. 3: Topology rules for the geology dataset (Pantelias et al., 2008).

- Feature dataset Geology: Geological data derived from four geological maps of 1:5.000 scale covering the study area. This feature dataset contains also linear features generated from airphotos interpretation.

- Feature dataset Engineering Geology: Geotechnical data derived from four geotechnical maps of 1:5.000 scale covering the study area. This dataset contains also data coming from specific survey, observations and soil mechanics, rock mechanics laboratory tests for the determination of physical and mechanical properties of the penetrated formations.

- Feature dataset Neotectonics: Neotectonic data derived from detailed field mapping and observations.

- Feature dataset Hydrogeology: Hydrogeological data concerning water chemical analyses and piezometric contours.

- Feature dataset Geophysics: Geophysical data comprising gravity - seismic - electrical electromagnetical measurements

- Feature dataset Soils: Soil geochemical data derived from field sampling and laboratory analyses.

- Feature dataset Marine Geology: Data coming from marine geology survey (Bathymetry, morphology, sampling).

- Feature dataset Radioactive elements: Data concerning radon measurements

- Feature dataset Geoarchaeology: Data derived from geoarchaeological survey in the broader area of Nafplio.

As mentioned above, the customized geodatabase contains also special elements that contribute to the best data management and integrity. These elements are topology ${ }^{1}$, domains ${ }^{2}$, subtypes ${ }^{3}$ and re-

\footnotetext{
${ }^{1}$ In geodatabases Topology constitutes the arrangement that constrains how point, line, and polygon features share geometry (ArcGIS Desktop help).

${ }^{2}$ Attribute domains are used to constrain the values allowed in any particular attribute for a table or feature class. A domain is a declaration of acceptable attribute values (ArcGIS Desktop help).

${ }^{3}$ Subtypes are records in a table or feature class that have been grouped based on an attribute field. Subtypes are implemented by creating coded values and, therefore, must be associated with fields of the data type short or long integer (ArcGIS Desktop help).

${ }^{4}$ An item in the geodatabase that stores information about a relationship. Relationship classes define relationships between objects in the geodatabase. These relationships can be simple one-to-one relationships or more complex one-to-many (or many-to-many) relationships between features and table rows. (ArcGIS Desktop help).
} 


\begin{tabular}{|c|c|}
\hline \multirow{2}{*}{$\begin{array}{c}\text { GEOLOGICAL LINEAR } \\
\text { FEATURES (SUBTYPES) }\end{array}$} & BOUNDARIES \\
\cline { 2 - 2 } & $\begin{array}{c}\text { FAULTS } \\
\text { OTHER TECTONIC LINES (e.g. overthrusts, upthrusts, tec- } \\
\text { tonic contacts) ) }\end{array}$ \\
\cline { 2 - 2 } & SPECIAL GEOLOGICAL LINES (e.g. landslide lines) \\
\hline
\end{tabular}

Fig. 4: Subtypes for the geology dataset (Pantelias et al., 2008).

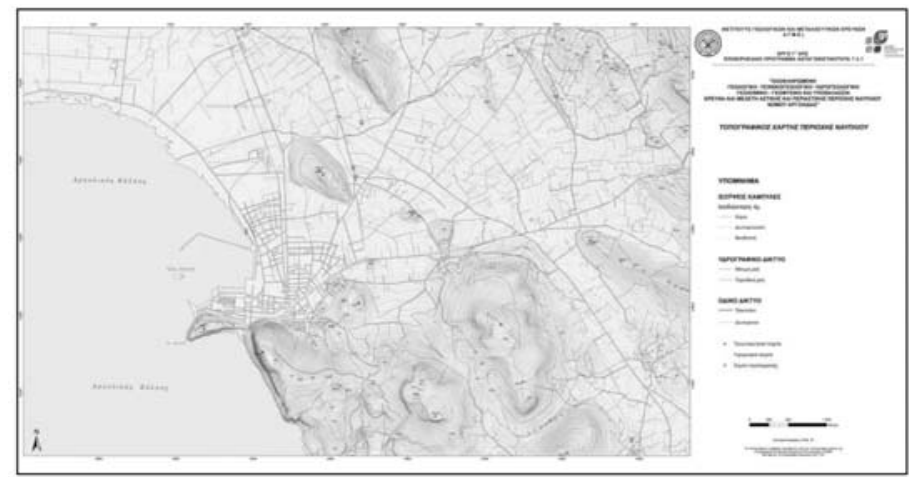

Fig. 5: Topographic map of the study area.

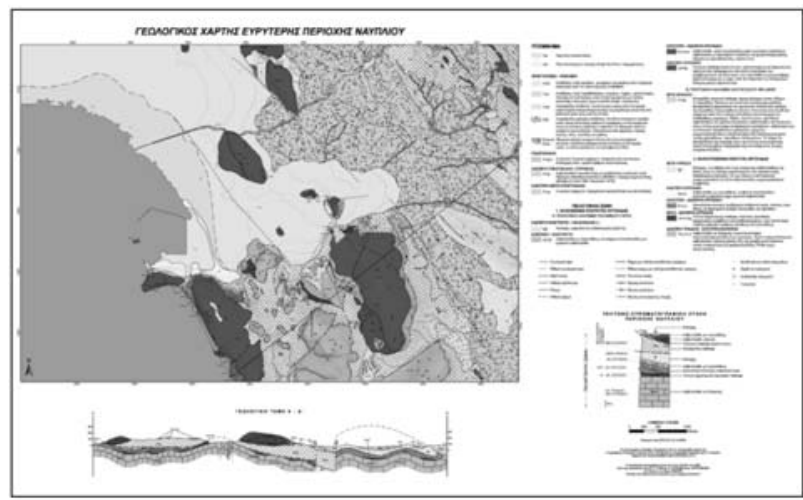

Fig. 6: Geological map of the study area (Photiades, 2008).

lationship classes ${ }^{4}$. In summary, they:

- provide a strong mechanism to perform integrity checks on data.

- help to validate and maintain better feature representations in the geodatabase.

- enable richer and more efficient analytical functions in Geographic Information System.

Subtypes and topology rules for the geology dataset are presented below (Fig. 3 and 4).

\subsection{Derived digital cartographic products}

Urban planning process is complex, but an effective urban strategy involves land-use planning to guide development and appropriate use of land areas.

Geothematic cartographic products and especially maps are used effectively towards this scope. 


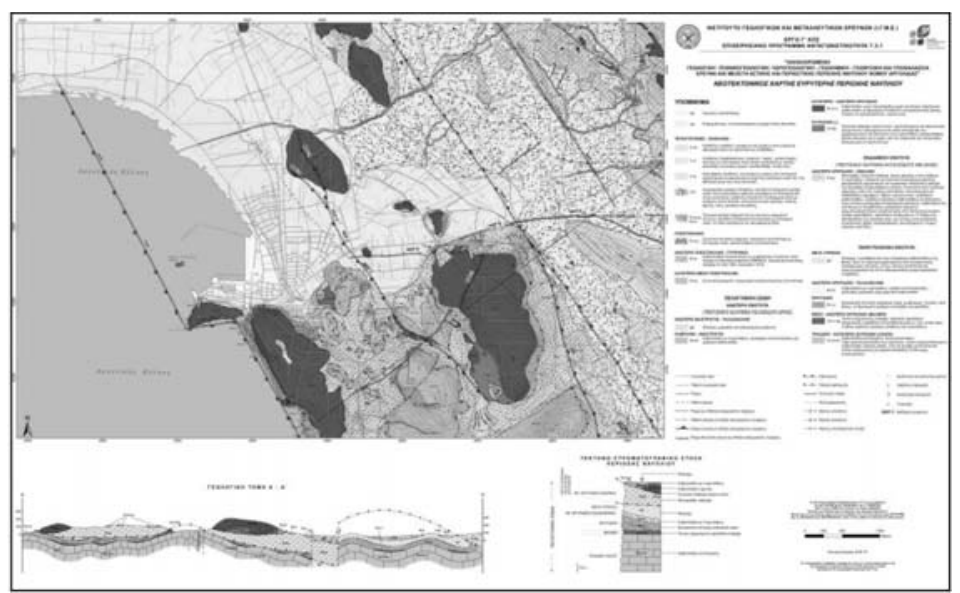

Fig. 7: Neotectonic map of the study area (Galanakis and Georgiou, 2008).

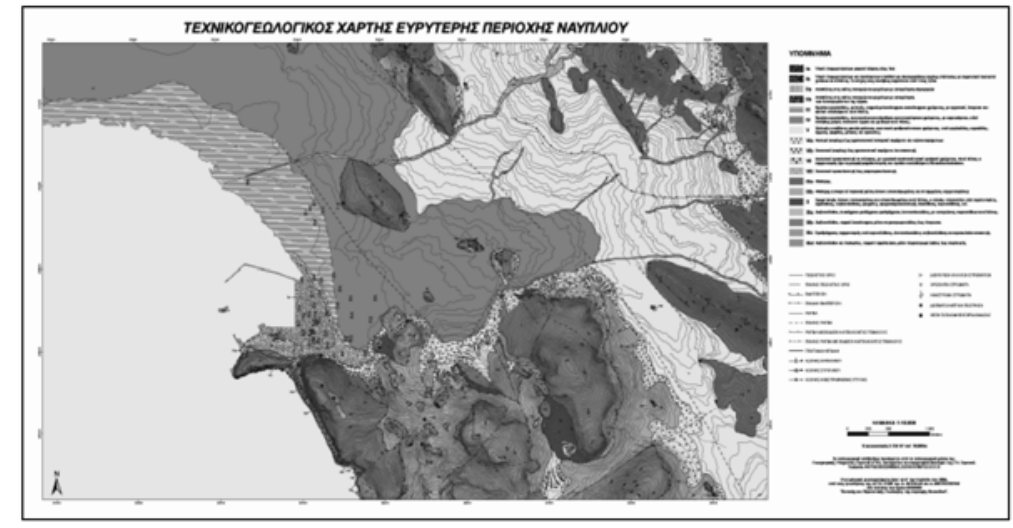

Fig. 8: Engineering geological map of the study area (Apostolidis and Koutsouveli, 2008).

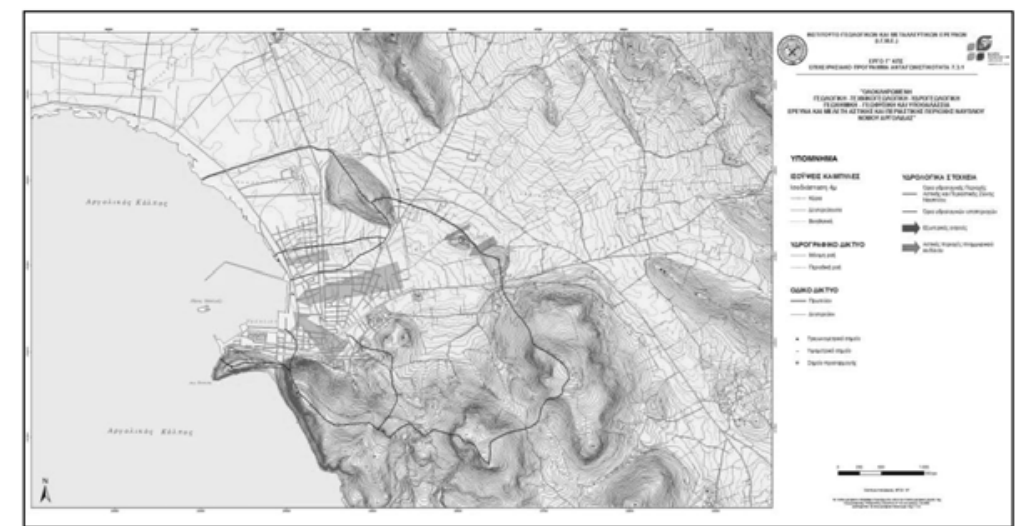

Fig. 9: Hydrological map of the study area (Sampatakakis et al., 2009). 


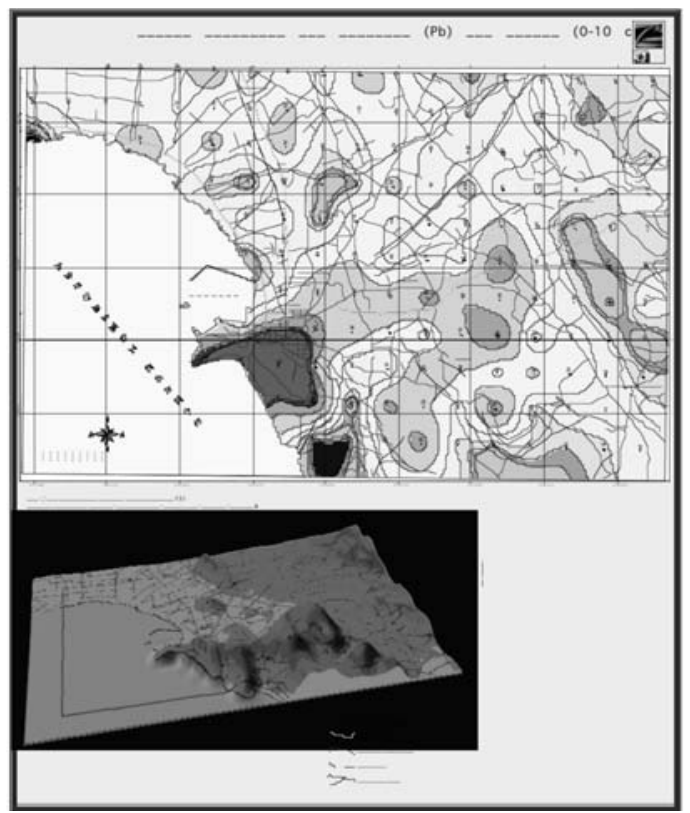

Fig. 10: Geochemical map displaying the $\mathrm{Pb}$ spatial distribution in soil in the study area (Tassiou, 2008; Vassiliades, 2008).

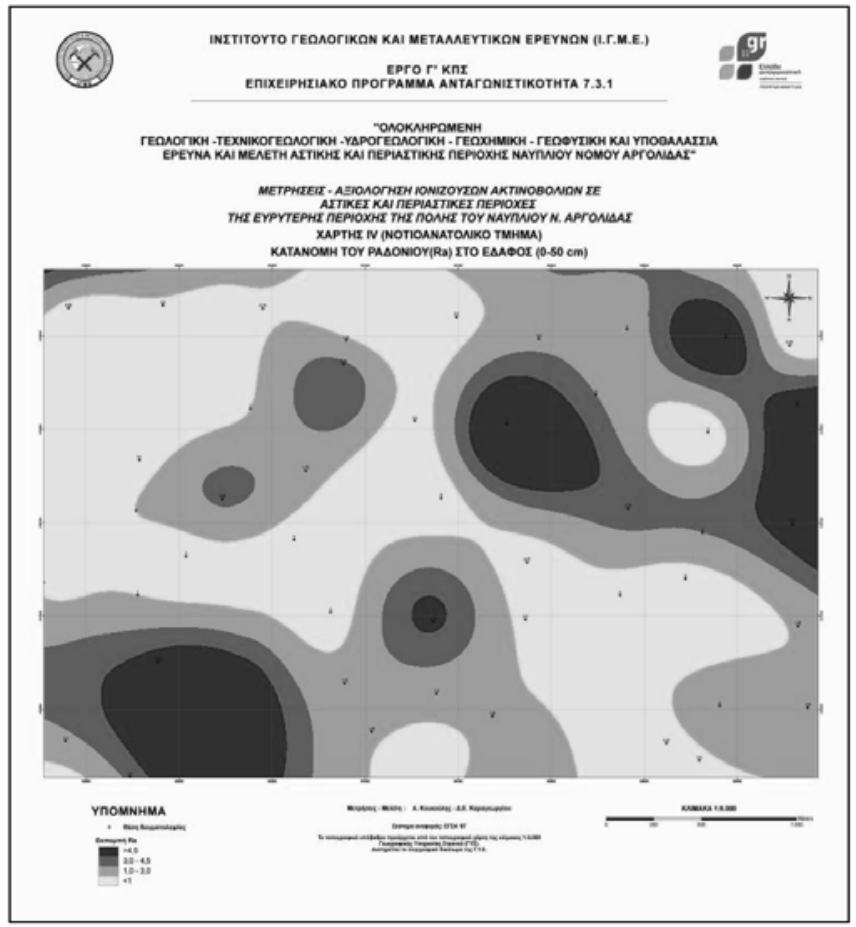

Fig. 11: Map displaying the Radon concentration in soil in the study area (Koukoulis and Karageorgiou, 2008)). 

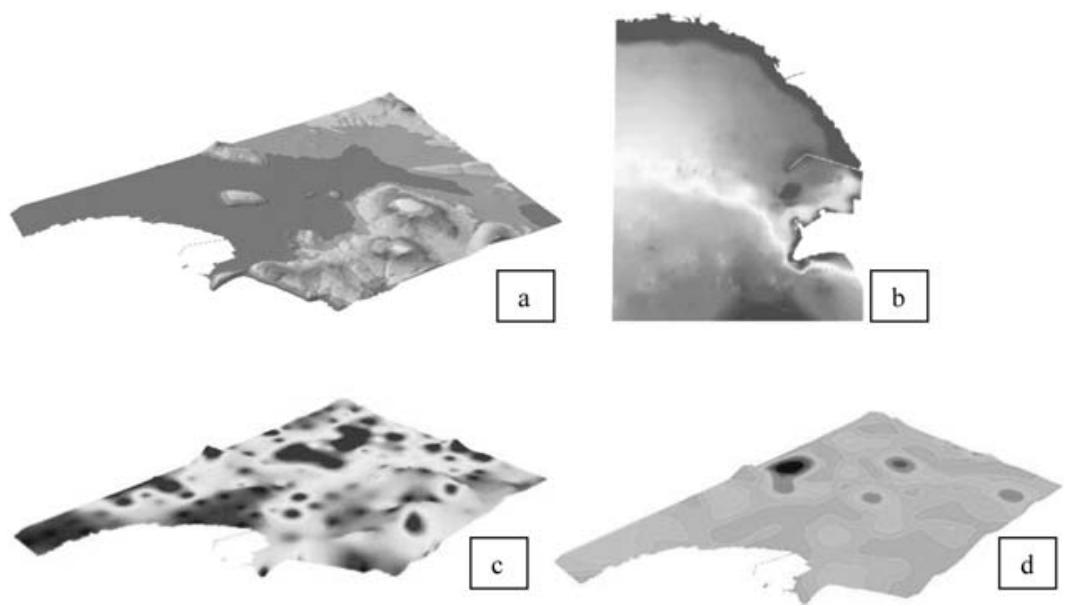

Fig. 12: (a) High detailed TIN displaying the surface morphology of the study area, (b) raster representing the seafloor morphology of the marine area near the city of Nafplio (Argolic Gulf) (Andrinopoulos et al., 2008), (c) raster representing the radon concentration in soil in the study area (Koukoulis and Karageorgiou, 2008), (d) raster representing the $\mathrm{Cu}$ spatial distribution in soil in the study area (Tassiou, 2008; Vassiliades, 2008).

Specifically, they constitute a powerful tool for urban planning by:

- providing specific geoinformation about particular locations.

- providing general information about geospatial patterns.

- giving the opportunity to compare patterns on two or more maps.

- providing identification of specific uses for designated sites.

- providing identification of suitable areas for urban or regional development.

In the framework of Urban Geology Project of IGME, all collected and processed data from field surveys, desk surveys, monitoring, terrain and laboratory analysis are presented in a form that is accessible to all, in a set of thematic maps and other digital 2D and 3D data representing the morphology, geology, hydrogeology, ground conditions, tectonics, hazards, and so on of the study area of Nafplio (Fig. 5 - 12).

\section{Conclusions}

Urban Geology studies rely on diverse branches of earth sciences such as hydrology, engineering geology, geochemistry, stratigraphy, geomorphology etc. The geoscience information derived from various sources is compiled in a digital format and stored in georeferenced databases in the form of point, linear, and polygon data. This information constitutes the geoscience knowledge base which is then processed by Geographic Information Systems (GIS) to integrate the various sources of information and produce derived graphics, maps and models describing the geological infrastructure and response of the geological environment to human activities.

Urban Geology project of I.G.M.E. accomplished in the framework of CSF 2000 - 2006, focused on the compilation and integration of such data. Specialized and dedicated studies took place at four 
pilot urban areas. Nafplio, the capital city of Argolis prefecture, was one of them.

Geographic Information Systems provided the best environment for the collection, storage, management, processing, analysis and cartographic representation of complex geoscientific information. All compiled data, stored in specially customized geodatabase, were classified in geothematic layers (feature classes), grouped in geothematic datasets (feature datasets) and processed in order to produce multifunctional surfaces and geothematic maps. Special geodatabase elements such as topology, domains, subtypes and relationship classes were used for the best data management and integrity.

All collected and processed data from field surveys, desk surveys, monitoring and laboratory analysis are presented in a form that is accessible to all, in a set of thematic maps and other digital 2D and 3D data, representing the morphology, geology, hydrogeology, ground conditions, tectonics, hazards etc. in the specific study area.

\section{Acknowledgements}

This study was accomplished within the framework of the project "Collection and Documentation of Geothematic Information for Urban and Suburban areas in Greece - Pilot Applications". The program was funded by the Operational Program "Competitiveness" Priority Axis 7: Energy and Sustainable Development, Measure 7.3: Exploitation of natural resources and support in meeting environmental commitments. The Operational Program "Competitiveness" was co-funded by the European Regional Development Fund (ERDF).

We would like to thank all colleagues who participated in this multidisciplinary project: Andrinipoulos A., Apostolidis E., Chiotis E., Chiras S., Demetriades A., Efthimiou G., Filos G., Galanakis D., Ganotis G., Georgiou Ch., Iordanidis S., Karageorgiou D., Karmis P., Karpetas Th., Kokkalis Th., Kostopoulos A., Koukis G., Koukoulis A., Kousoulas F., Koutsouveli A., Kyriakopoulos Th., Lappas I., Letsios K., Loupasakis C., Manazis St., Mastrogiannis F., Michalopoulos N., Mitropoulos D., Moraiti E., Nikolaides M., Nikolakopoulos K., Nikolaou N., Panagopoulos A., Pantelias E., Paraschakis Th., Photiades A., Pisinas K., Polyzou L., Sampatakakis P., Spyropoulos I., Tassiou S., Tsiounis E., Tzoumas S., Vassiliades E., Vertsiotis V., Zacharaki P., Zagouroglou C., Zananiri I. and Zimianitis E. Special acknowledgment is granted to the team of the Geodynamics Institute of the National Observatory of Athens (scientific responsible: Karastathis V.) and the geologists Hademenos V., Maroulakis Sp. for their systematic work and support.

\section{References}

Andrinopoulos, A., Zacharaki, E., Zimianitis, E., Maroulakis, S., Mitropoulos, D. and Efthimiou, G., 2008. Marine geological study of the Northern Argolic gulf. Technical report, IGME, Athens, Greece.

Apostolidis, E. and Koutsouveli, A., 2008. Engineering geological map of the urban and suburban area of Nafplio city. Technical report, IGME, Athens, Greece.

ArcGIS Desktop Help, 1999-2008, ESRI.

Bélanger, J.R. and Moore, C.W., 1999. The use and value of Urban Geology in Canada: A case study in the National Capital Region. Geoscience Canada, Vol. 26, № 3. Available online at: http://gsc.nrcan.gc.ca/urbgeo/natcap/pdf/urbangeologypub.pdf

Galanakis, D. and Georgiou, Ch., 2008. Neotectonic study of the urban and suburban area of Nafplio city (pilot application). Technical report, IGME, Athens, Greece.

Goodchild, M.F. and Kemp, K.K. (eds.), 1990. Spatial databases as models of reality, NCGIA Core Curriculum in GIS, Unit 10, National Center for Geographic Information Analysis, University of Cali- 
fornia, Santa Barbara CA. Available online at: http://www.geog.ubc.ca/ courses/klink/ gis.notes/ncgia/u10.html

Hancock, P. and Skinner, B.J., 2000. Urban Geology. The Oxford Companion to the Earth. Oxford University Press. Available online at: http://www.encyclopedia.com/doc/10112-urbangeology.html

Koukoulis, A. and Karegeorgiou, D.E., 2008. Measurements - evaluation of ionizing radiation in urban and suburban areas of Nafplio city. Technical report, IGME, Athens, Greece.

Legget, R.F., 1973. Cities and Geology. McGraw Hill, New York. p. p. 624.

Legget, R.F. and Karrow, P.F., 1983. Handbook of Geology in Civil Engineering. McGraw- Hill, New York.

Pantelias, E., Zervakou, A., Tsombos, P. and Nikolakopoulos, K., 2008. Spatial database for the management of Urban Geology geothematic information: the case of Drama City, Greece. Proceedings, $15^{\text {th }}$ International Symposium on Remote Sensing of the International Society for Optical Engineering, September 15-19, Cardiff, Wales, United Kingdom, Proc. SPIE, Vol. 7110.

Photiades, A., 2008. Geological study of the urban and suburban pilot area of Nafplio city, Argolis prefecture. Technical report, IGME, Athens, Greece.

Sampatakakis, P., Koukis, G. and Lappas, I., 2009. Hydrogeological and Hydrological study of the urban and suburban area of Nafplio. Technical report, IGME, Athens, Greece.

Tan, B.K. and Komoo I., 1990. Urban Geology: Case study of Kuala Lumpur, Malaysia. Engineering Geology. Elsevier Science Publishers, B.V 28, 71-94.

Tassiou, S., 2008. Geochemical environmental study of the urban and suburban area of Nafplio, Argolis prefecture - Vol. 1 Interpretation. Technical report, IGME, Athens, Greece.

Vassiliades, E., 2008. Geochemical environmental study of the urban and suburban area of Nafplio, Argolis prefecture - Vol. 2 Geochemical maps. IGME, Athens, Greece.

Zervakou, A., Tsombos, P. and Nikolakopoulos, K., 2007. Urban Geology: Documentation of geo-thematic information for urban areas in Greece: the case of Nafplio. Proceedings, $14^{\text {th }}$ International Symposium on Remote Sensing of the International Society for Optical Engineering, September17-20 , Palazzo degli Affari Conference Ctr., Florence, Italy, Proc. SPIE, Vol. 6749 p. 67491G1-12.

Zervakou, A., Tsombos, P. and Nikolakopoulos, K., 2008. Urban Geology and GIS: The example of IGME. $5^{\text {th }}$ Greek Conference HellasGIs: «GIS and Environment», December 4-5, Athens, Greece. 